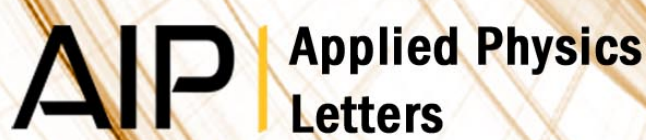

\section{Nucleation of $\beta F e S i 2$ nanostructures at pinned step bunches on the $\mathrm{Si}(111)$ surface}

R. P. Brady, A. S. Sharma, R. L. Giblet, R. J. Cottier, T. D. Golding et al.

Citation: Appl. Phys. Lett. 86, 223102 (2005); doi: 10.1063/1.1940128

View online: http://dx.doi.org/10.1063/1.1940128

View Table of Contents: http://apl.aip.org/resource/1/APPLAB/v86/i22

Published by the American Institute of Physics.

Additional information on Appl. Phys. Lett.

Journal Homepage: http://apl.aip.org/

Journal Information: http://apl.aip.org/about/about_the_journal

Top downloads: http://apl.aip.org/features/most_downloaded

Information for Authors: http://apl.aip.org/authors

\section{ADVERTISEMENT}




\title{
Nucleation of $\beta-\mathrm{FeSi}_{2}$ nanostructures at pinned step bunches on the $\mathrm{Si}(111)$ surface
}

\author{
R. P. Brady, A. S. Sharma, R. L. Giblet, R. J. Cottier, T. D. Golding, and J. M. Perez ${ }^{\text {a) }}$ \\ Department of Physics, University of North Texas, Denton, Texas 76203
}

(Received 11 January 2005; accepted 21 April 2005; published online 24 May 2005)

\begin{abstract}
We report the preferential nucleation and synthesis of $\beta-\mathrm{FeSi}_{2}$ nanostructures at pinned step bunches on the $\mathrm{Si}(111)$ surface. The nanostructures are synthesized by depositing $\mathrm{Fe}$ on $\mathrm{Si}$ at room temperature and subsequent annealing. The surface topography is studied using scanning tunneling microscopy and atomic force microscopy. The size, shape and orientation of the nanostructures indicate that the phase is the semiconducting $\beta-\mathrm{FeSi}_{2}$ phase. () 2005 American Institute of Physics.

[DOI: $10.1063 / 1.1940128$ ]
\end{abstract}

Nanostructures such as quantum dots (QDs) and nanowires have optical and electronic properties that can be tuned by changing their size. Such nanostructures have applications in lasers, light-emitting diodes and sensors. ${ }^{1}$ Silicon is the most commonly used material for microelectronic applications. Therefore, there has been considerable interest in the growth of silicide nanostructures on $\mathrm{Si}$ such as metallic $\mathrm{TiSi}^{2}{ }^{2} \mathrm{CoSi}_{2},{ }^{3} \mathrm{NiSi}^{4}{ }^{4}$ and $\mathrm{FeSi}$ (Ref. 5) QDs and nanowires. The semiconducting iron disilicide phase, $\beta-\mathrm{FeSi}_{2}$, is an especially promising material for optoelectronic applications because its band gap of $\sim 0.87 \mathrm{eV}$ corresponds to a wavelength of $1.55 \mu \mathrm{m}$ used for optical communications. ${ }^{6-11} \mathrm{Re}-$ cently, ion-beam synthesized $\beta-\mathrm{FeSi}_{2}$ precipitates in $\mathrm{Si}$ have been shown to produce electroluminescence at $\sim 1.5 \mu \mathrm{m}$ at room temperature (RT). ${ }^{10}$ In this letter, we report, the preferential nucleation and synthesis of $\beta-\mathrm{FeSi}_{2}$ nanostructures at pinned step bunches on the Si (111) surface. The nanostructures are synthesized by depositing Fe at RT on a $\mathrm{Si}$ (111) surface having pinned step bunches followed by annealing. Using scanning tunneling microscopy (STM) in ultrahigh vacuum (UHV) and atomic force microscopy (AFM) in air, we study in detail the nucleation, size, shape and orientation of the nanostructures.

The substrates used for these studies were boron-doped Si (111) wafers miscut by $1^{\circ}$ toward [ $\left.1 \overline{1} 2\right]$. Iron was deposited using an e-beam evaporator in a growth chamber that is coupled to a STM chamber. The chambers are at a base pressure of $1 \times 10^{-10}$ Torr. The substrates were cleaned in the growth chamber by flash heating them to approximately $1100{ }^{\circ} \mathrm{C}$ for $10 \mathrm{~s}$ by applying a direct current through them. During heating, the pressure in the growth chamber momentarily rose to about $5 \times 10^{-9}$ Torr due to outgassing. After cooling, the substrates were transferred under UHV to the STM chamber and imaged to verify a $7 \times 7$ reconstruction. The substrates were then transferred to the growth chamber, exposed to $\mathrm{Fe}$ and annealed. After cooling, the samples were transferred back to the STM chamber and imaged. Tunneling currents of $1 \mathrm{nA}$ with a sample bias of $1-1.5 \mathrm{~V}$ were used. The surface microstructure was also studied using AFM in air.

On the Si (111) surface, step pinning occurs due to sublimation-induced step flow, which is impeded by carbide

\footnotetext{
a) Author to whom correspondence should be addressed; electronic mail: jperez@unt.edu
}

impurities formed by annealing near $1100{ }^{\circ} \mathrm{C} .{ }^{12-14}$ Latyshev et al. ${ }^{15}$ showed that pinning of steps by contaminant adsorbates occurs on the $\mathrm{Si}$ (111) surface when the sample is annealed after a short exposure to poor vacuum. In our experiments, we observe using AFM that pinning of steps occurs during the high temperature cleaning process as a result of the momentary rise in pressure to $5 \times 10^{-9}$ Torr due to outgassing. The pinned step bunches consist of 2-10 single atomic steps.

Figure 1(a) shows a UHV STM image of a sample prepared by depositing about $1 \mathrm{ML}$ of $\mathrm{Fe}$ at RT on a Si (111) substrate prepared as described above, followed by annealing at $500{ }^{\circ} \mathrm{C}$ for $15 \mathrm{~min}$ and then $650{ }^{\circ} \mathrm{C}$ for $20 \mathrm{~min}$. Observed are nanostructures on the $\mathrm{Si}$ (111) $7 \times 7$ surface that have a long axis oriented along one of the $\mathrm{Si}\langle 110\rangle$ directions that
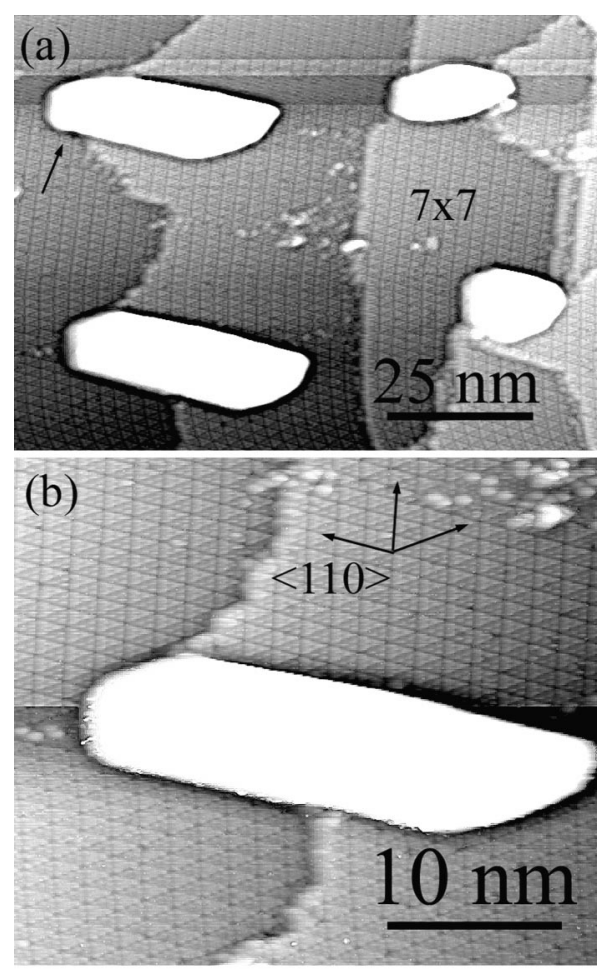

FIG. 1. (a) UHV STM image of a Si (111) surface after deposition of $1 \mathrm{ML}$ of Fe at RT followed by annealing at $500{ }^{\circ} \mathrm{C}$ for $15 \mathrm{~min}$ and then $650{ }^{\circ} \mathrm{C}$ for $20 \mathrm{~min}$. Nanostructures are observed at step pinning sites. (b) Close-up of (a) showing alignment of a nanostructure along one of the $\mathrm{Si}\langle 110\rangle$ directions. 


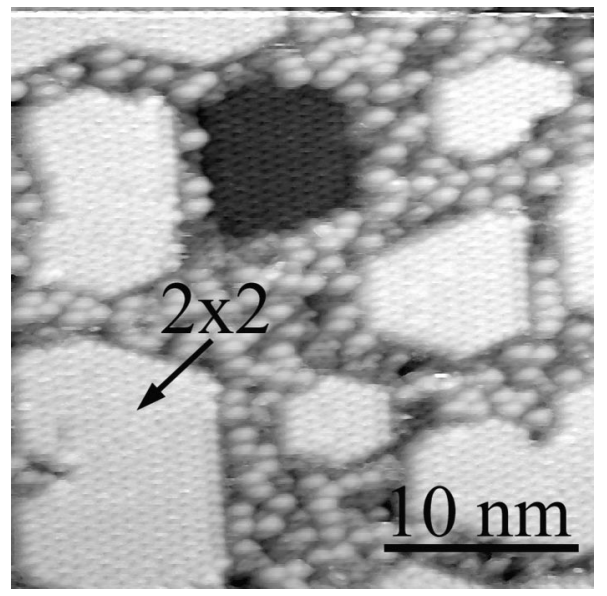

FIG. 2. UHV STM image of the sample shown in Fig. 1 after annealing at $500{ }^{\circ} \mathrm{C}$ for $15 \mathrm{~min}$ and before annealing at $650{ }^{\circ} \mathrm{C}$. Observed are thin metastable $\mathrm{FeSi}_{2}$ layers that have a $2 \times 2$ reconstruction. The $\mathrm{FeSi}_{2}$ layers are separated by amorphous regions.

make an angle of $60^{\circ}$ with each other, as shown in Fig. 1(b). The nanostructures nucleate at the pinning sites of step bunches consisting of approximately $3-5$ single atomic steps, as indicated by the arrow in Fig. 1(a). The nanostructures are three-dimensional (3D) having lengths of approximately 10-40 nm, widths of 9-12 nm and heights of about $5 \mathrm{~nm}$.

The nanostructures in Fig. 1 have the same size, shape and orientation as $\beta$-FeSi $i_{2}$ nanostructures reported by Shao and Homewood $^{11}$ that precipitate in $\mathrm{Si}$ as a result of $\mathrm{Fe}$ implantation followed by annealing. In Ref. 11, transmission electron microscopy studies of the nanostructures showed that they have lengths of approximately 10-20 nm, a long axis oriented in the $\mathrm{Si}\langle 110\rangle$ directions, and a crystallographic structure corresponding to $\beta-\mathrm{FeSi}_{2}$. The average length/width ratio of the nanostructures in Fig. 1 is $2.8 \pm 0.7$, which compares well with the average length/width ratio of nanostructures in Ref. 11 of $3.0 \pm 1.2$. The normal to the $\beta-\mathrm{FeSi}_{2}(001)$ plane should be orthogonal to the $\mathrm{Si}(111)$ substrate, ${ }^{11}$ which is consistent with our observations. We propose that the nanostructures observed in Fig. 1 are $\beta-\mathrm{FeSi}_{2}$ since they have the same size, shape and orientation as the nanostructures in Ref. 11 .

We find that initially annealing the sample at $500{ }^{\circ} \mathrm{C}$ after $\mathrm{Fe}$ deposition is necessary to observe $\beta$ - $\mathrm{FeSi}_{2}$ nanostructures as shown in Fig. 1 . Annealing at $500{ }^{\circ} \mathrm{C}$ results in a surface that is covered by $2 \times 2$ reconstructed layers that have a nearest-neighbor distance of $7.6 \AA$ and thickness $\leqslant 3 \AA$, as shown in Fig. 2. Such layers have been previously reported and attributed to a metastable $\mathrm{FeSi}_{2}$ phase that is stabilized by surface strain. ${ }^{8,9}$ For $\mathrm{FeSi}_{2}$ layers having a thickness $\gtrsim 2 \mathrm{~nm}$, a transition from the metastable to $\beta$-FeSi 2 phase has been observed. ${ }^{8}$ We propose that when the sample is subsequently annealed at $650{ }^{\circ} \mathrm{C}$, atoms in metastable $\mathrm{FeSi}_{2}$ layers diffuse and accumulate at pinning sites forming $3 \mathrm{D} \beta-\mathrm{FeSi}_{2}$ islands.

Figure 3 shows a $2 \times 2 \mu \mathrm{m}^{2}$ AFM image of a sample prepared by depositing about $6 \mathrm{ML}$ of Fe at RT on a Si (111) substrate prepared as described above, followed by annealing at about $500{ }^{\circ} \mathrm{C}$ for $12 \mathrm{~h}$ and then $850{ }^{\circ} \mathrm{C}$ for $1 \mathrm{~h}$. Observed in Fig. 3 are pinned step bunches that have an average height of $\sim 5 \mathrm{~nm}$. At the pinning sites, crystallites are observed that have the same shape and orientation as the smaller nanostructures in Fig. 1. The crystallites have a long axis oriented

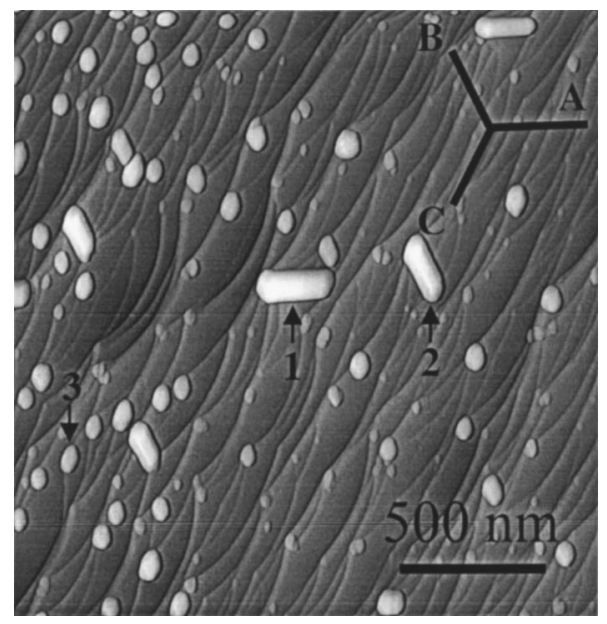

FIG. 3. AFM image of a Si (111) surface after deposition of $6 \mathrm{ML}$ of Fe at RT followed by annealing at $500^{\circ} \mathrm{C}$ for $12 \mathrm{~h}$ and then $850{ }^{\circ} \mathrm{C}$ for $1 \mathrm{~h}$.

along one of three directions, denoted by A, B and C in Fig. 3 , which make an angle of $60^{\circ}$ with each other. Examples of crystallites in the $\mathrm{A}, \mathrm{B}$ and $\mathrm{C}$ directions are indicated by arrows 1, 2 and 3, respectively, in Fig. 3. Crystallites in the A direction have lengths of approximately 200-300 nm, widths of 70-100 nm and heights of 20-25 nm. Crystallites in the B direction have lengths of 100-200 nm, widths of 60-90 nm and heights of 10-20 $\mathrm{nm}$. Crystallites in the $\mathrm{C}$ direction have lengths below $100 \mathrm{~nm}$, widths of 60-90 nm and heights of $10-15 \mathrm{~nm}$. The average length/width ratio of the nanostructures in the A and B directions is $2.9 \pm 0.2$. In Figs. 1 and 3, the growth of the nucleated structures seems to avoid the long axis parallel to the average step direction. However, it seems much more likely that the nucleation is induced by the carbide pinning site rather than the step grouping.

We suggest that the pinned step bunches in Fig. 3 are higher than those in Fig. 1 due to the pinning of additional steps as a result of step motion that occurs when the sample is annealed at $850{ }^{\circ} \mathrm{C}$ for $1 \mathrm{~h}$. To minimize surface energy, higher step bunches result in wider terraces. ${ }^{14}$ The wider terraces and greater amount of deposited Fe result in the growth of larger crystallites, as observed in Fig. 3. Annealing at temperatures greater than $850{ }^{\circ} \mathrm{C}$, results in evaporation of the nanostructures.

A meter stick used to determine the length scale at which quantum confinement occurs is the exciton Bohr diameter $d_{x}=2 \hbar^{2} \varepsilon_{D} \varepsilon_{0} / \mu^{*} q_{e}^{2}$, where $q_{e}$ is the charge of the electron, $\varepsilon_{0}$ is the permitivity, $\varepsilon_{D}$ is the dielectric constant, and $\mu^{*}$ is the exciton reduced mass given by $1 / \mu^{*}=1 / m_{e}+1 / m_{h}$ where $m_{e}$ and $m_{h}$ are the electron and hole effective masses, respectively. For $\beta$-FeSi $i_{2}, m_{e}=0.49 m_{0}, m_{h}=1.0 m_{0}$, where $m_{0}$ is the free electron mass, and $\varepsilon_{D}=31.4{ }^{6,7}$ Using these values, $d_{x} \approx 10.0 \mathrm{~nm}$. We conclude that the nanostructures shown in Fig. 1 have dimensions where we would expect quantum confinement effects to play a significant role.

The pinning and bunching of steps on the Si (111) surface can be controlled by controlling the density of immobile adsorbates, direction of direct current during heating, annealing temperature and miscut angle. ${ }^{14-16}$ Such control has allowed the design of atomic step networks that can be used as templates $^{17-19}$ and guides ${ }^{16}$ for nanostructure growth. Controlling the pinned step pattern and amount of $\mathrm{Fe}$ deposited provides a method for controlling the pattern and size of $\beta$-FeSi $i_{2}$ nanostructures. 
In summary, we observe the nucleation and synthesis of $\beta$ - $\mathrm{FeSi}_{2}$ nanostructures at pinned step bunches on the $\mathrm{Si}(111)$ surface. The nanostructures are synthesized by depositing $\mathrm{Fe}$ at RT on a $\mathrm{Si}$ (111) surface having pinned step bunches, followed by annealing at $500{ }^{\circ} \mathrm{C}$ for 15 minutes and $650{ }^{\circ} \mathrm{C}$ for $20 \mathrm{~min}$. The nanostructures have sizes with dimensions necessary for spatial quantum confinement effects. By controlling the pinned step pattern and amount of Fe deposited, the pattern and size of $\beta-\mathrm{FeSi}_{2}$ nanostructures can be controlled.

The authors thank Ed Arnold, Danekar Koustubh, Han $\mathrm{Xu}$, Jeremy Hansen, Ruddy Potter, Jason Rejman and Gary Woodard for assistance, and Roberto Failla for the AFM image. This work was supported by the Texas Advanced Research Program under Award No. 003594-0074-2001 and the Office of Naval Research, Contract No. N00014-03-1-0820.

${ }^{1}$ See, for example, Quantum Dots and Nanowires, edited by S. Bandyopadhyay and H. S. Nalwa (American Scientific, Stevenson Ranch, CA, 2003).

${ }^{2}$ Z. He, M. Stevens, D. J. Smith, and P. A. Bennett, Surf. Sci. 524, 148 (2003).

${ }^{3}$ I. Goldfarb and G. A. D. Briggs, Phys. Rev. B 60, 4800 (1999).
${ }^{4}$ M. Yoshimura, I. Ono, and K. Ueda, Appl. Surf. Sci. 130, 276 (1998).

${ }^{5}$ A. Wawro, S. Suto, C. Czajka, and A. Kasuya, Phys. Rev. B 67, 195401 (2003).

${ }^{6}$ M. C. Bost and J. E. Mahan, J. Appl. Phys. 58, 2696 (1985).

${ }^{7}$ H. Lange, Phys. Status Solidi B 201, 3 (1997).

${ }^{8}$ J. Chevrier, V. Le Thanh, S. Nitsche, and J. Derrien, Appl. Surf. Sci. 56-58, 438 (1992).

${ }^{9}$ A. L. Vazquez de Parga, J. De La Figuera, C. Ocal, and R. Miranda, Ultramicroscopy 845, 42 (1992).

${ }^{10}$ D. Leong, M. Harry, K. J. Reason, and K. P. Homewood, Nature (London) 387, 686 (1997).

${ }^{11}$ G. Shao and K. P. Homewood, Intermetallics 8, 1405 (2000).

${ }^{12}$ Y.-N. Yang and E. D. Williams, J. Vac. Sci. Technol. A 8, 2481 (1990).

${ }^{13}$ Y.-N. Yang, E. Fu, and E. D. Williams, Surf. Sci. 356, 101 (1996).

${ }^{14}$ J. Ozcomert, W. Pai, N. Bartelt, and J. Reutt-Robey, Surf. Sci. 293, 183 (1993).

${ }^{15}$ A. V. Latyshev, A. L. Aseev, A. B. Krasilnikov and S. I. Stenin, Surf. Sci. 213, 157 (1989)

${ }^{16}$ J. Viernow, J.-L. Lin, D. Y. Petrovykh, F. M. Leibsle, F. K. Men, and F. J. Himpsel, Appl. Phys. Lett. 8, 948 (1998).

${ }^{17}$ T. Ogino, H. Hibino, and Y. Homma, Crit. Rev. Solid State Mater. Sci. 24, 227 (1999).

${ }^{18}$ A. Sgarlata, P. Szkutnik, A. Balzarotti, N. Motta, and F. Rosei, Appl. Phys. Lett. 83, 4002 (2003).

${ }^{19}$ H. Omi, Y. Homma, T. Ogino, S. Stoyanov, and V. Tonchev, J. Appl. Phys. 95, 263 (2004). 